1. U.S. DEFARTMENT OF

PNNL- 18873

Prepared for the U.S. Department of Energy

under Contract DE-AC05-76RL01830

\title{
Demonstration Assessment of Light-Emitting Diode (LED) Freezer Case Lighting in Albertsons Grocery in Eugene, OR
}

\section{EE Richman \\ JR Tuenge}

October 2009 


\title{
DISCLAIMER
}

This report was prepared as an account of work sponsored by an agency of the United States Government. Neither the United States Government nor any agency thereof, nor Battelle Memorial Institute, nor any of their employees, makes any warranty, express or implied, or assumes any legal liability or responsibility for the accuracy, completeness, or usefulness of any information, apparatus, product, or process disclosed, or represents that its use would not infringe privately owned rights. Reference herein to any specific commercial product, process, or service by trade name, trademark, manufacturer, or otherwise does not necessarily constitute or imply its endorsement, recommendation, or favoring by the United States Government or any agency thereof, or Battelle Memorial Institute. The views and opinions of authors expressed herein do not necessarily state or reflect those of the United States Government or any agency thereof.

\author{
PACIFIC NORTHWEST NATIONAL LABORATORY \\ operated by \\ BATTELLE \\ for the \\ UNITED STATES DEPARTMENT OF ENERGY \\ under Contract DE-AC05-76RL01830
}

Printed in the United States of America

Available to DOE and DOE contractors from the

Office of Scientific and Technical Information,

P.O. Box 62, Oak Ridge, TN 37831-0062;

ph: (865) 576-8401

fax: (865) 576-5728

email: reports@adonis.osti.gov

\begin{abstract}
Available to the public from the National Technical Information Service, U.S. Department of Commerce, 5285 Port Royal Rd., Springfield, VA 22161 ph: (800) 553-6847 fax: (703) 605-6900

email: orders@ntis.fedworld.gov

online ordering: http://www.ntis.gov/ordering.htm
\end{abstract}

This document was printed on recycled paper.

(9/2003) 


\section{Demonstration Assessment of Light-Emitting Diode (LED) Freezer Case Lighting in Albertsons Grocery in Eugene, OR}

Final Report prepared in support of the

U.S. DOE Solid-State Lighting GATEWAY

Technology Demonstration Program

Study Participants:

Pacific Northwest National Laboratory

U.S. Department of Energy

LED Power, Inc.

Aztec Energy Partners

PECI, Inc.

Eugene Water and Electric Board

EE Richman

JR Tuenge

October 2009

Prepared for the U.S. Department of Energy under Contract DE-AC05-76RL01830

Pacific Northwest National Laboratory

Richland, Washington 99352 


\section{Preface}

This document is a report of observations and results obtained from a lighting demonstration project conducted under the U.S. Department of Energy (DOE) SSL GATEWAY Technology Demonstration Program. The program supports demonstrations of high-performance solid-state lighting (SSL) products in order to develop empirical data and experience with in-the-field applications of this advanced lighting technology. GATEWAY focuses on providing a source of independent, third-party data for use in decision-making by lighting users and professionals; this data should be considered in combination with other information relevant to the particular site and application under examination. Each GATEWAY demonstration compares one SSL product against the incumbent technology used in that location. Depending on available information and circumstances, the SSL product may also be compared to alternate lighting technologies. Though products demonstrated in the GATEWAY program have been prescreened and tested to verify their actual performance, DOE does not endorse any commercial product or in any way guarantee that users will achieve the same results through use of these products. 


\section{Executive Summary}

A retrofit of freezer cases at the Eugene, OR Albertsons store \#507 indicates a potentially successful application of light-emitting diode (LED) technology with additional energy savings from the use of occupancy sensors. Total energy savings (including more efficient light source, reduced consumption from occupancy sensors, and reduced demand on the compressor) is estimated to be $2,659 \mathrm{kWh}$ per year for a typical 5-door case. At Eugene electricity rates $(\$ 0.0827 / \mathrm{kWh})$, the calculated simple payback from energy savings alone is approximately 6.3 years. Maintenance savings are typically specific to each application and will not be the same for other applications. For this demonstration retrofit, maintenance savings are estimated to further reduce the payback to approximately 5.4 years. A complete simple payback analysis that might also include utility rebates and maintenance savings could be much shorter. Current Eugene area Utility rebates and Oregon tax credits could further reduce the payback period to about 1.6 years.

The logistics of arranging this comparison test did not allow for relamping of the existing fluorescent case lighting prior to the test and therefore a small portion of the apparent savings may be attributable to fluorescent lumen depreciation. It is more important to note that while the power consumed by the LED system showed a $61 \%$ reduction from that of the fluorescent system, a significant portion of the savings has resulted from a $36 \%$ reduction in illuminance as determined by relative measured levels before and after the retrofit. ${ }^{1}$ This $36 \%$ light level reduction accounts for more than half of the savings, which may have been alternatively accomplished with a retrofit of different fluorescent technology in the form of a lower output lamp and/or lower driving ballast. However, the complete retrofit demonstrated here that incorporates step dimming based on occupancy would be difficult with fluorescent technology given the limited market offerings of specific dimming ballast technology.

It is also important to consider that other potential attributes of the LED application in freezer cases make it a potentially better retrofit than adjusted fluorescent lighting. These include potentially longer life and reduced freezer case heat load that contributes to additional savings with LED technology. The potential for savings from reduced freezer case heat load due to lighting is difficult to measure because of the number of variables affecting individual freezer case installations, so was only estimated in this analysis.

The uniformity of light distributed within the case was also evaluated and found to be generally comparable to the fluorescent system. It is commonly believed that the directional nature of LED light emission means that much higher uniformity can be achieved compared with the omni-directional light emission of a fluorescent system. However, in product cases

\footnotetext{
${ }^{1}$ The application of lower light level LED strips was the result of a conscious choice by the Albertsons store to provide an appropriate level of illumination at a preferred cost. It is common for refrigeration and freezer cases to be lighted above typical industry recommendations, and this planned retrofit to LED technology provided the opportunity to adjust and correct the corresponding levels at this location.
} 
where widely varying package graphics and colors are the norm, the limited personal observation from this study revealed little noticeable difference among cases due to varying distribution uniformity. 


\section{Contents}

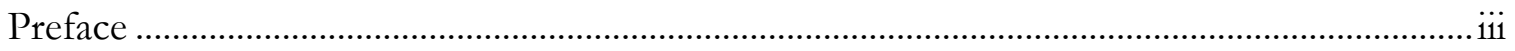

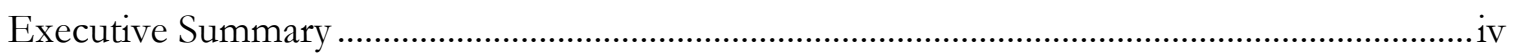

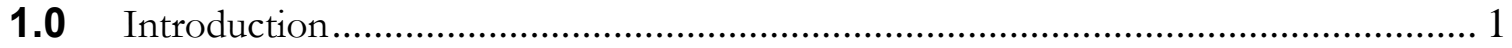

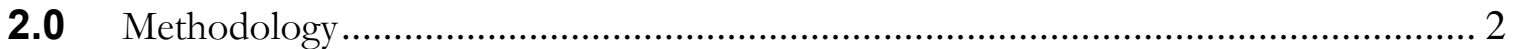

2.1 Site Description ...................................................................................... 2

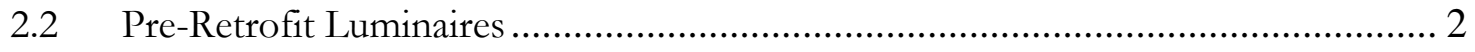

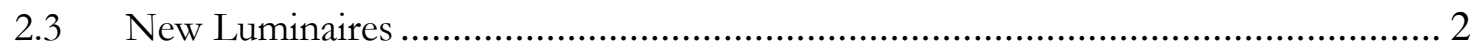

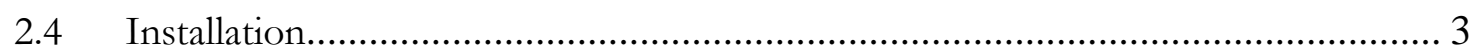

2.5 Luminance Measurement.............................................................................. 4

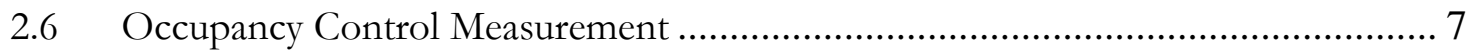

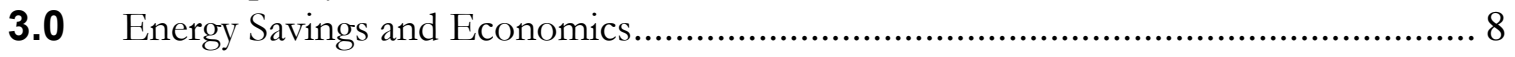

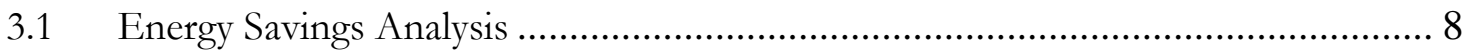

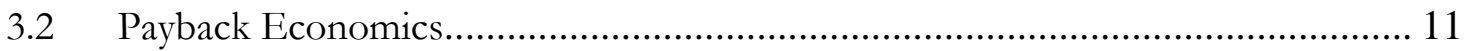

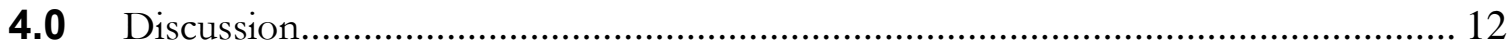

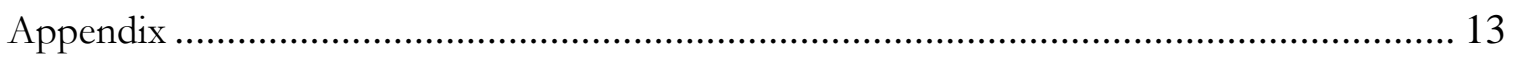

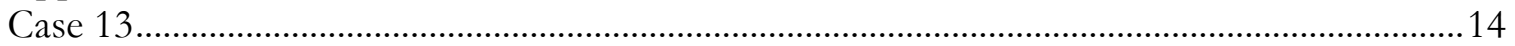

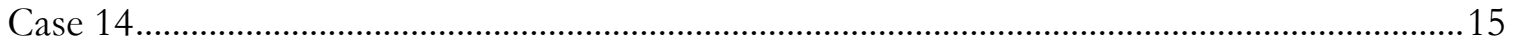

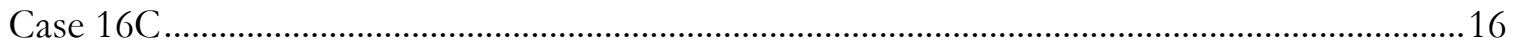

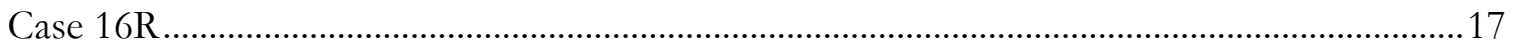




\section{Figures}

Figure 1. Top of LED Power LED strip as installed.................................................. 3

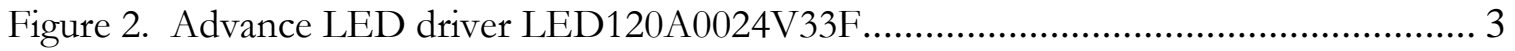

Figure 3. LED strip installation starting at one end of row ........................................ 4

Figure 4. Luminance measurement of white test surface inside of case ............................. 6

Figure 5. White test card inside of case with measurement locations ................................. 6

Figure 6. Hobo Light Level Logger installed at top of new LED light strip. ....................... 7

Figure 7. Side-by-Side Fluorescent (left) to LED (Right) Comparison .............................. 12

\section{Tables}

Table 1 Summary of Energy Savings for Single 5-door Refrigerated Case ...........................8

Table 2 Sample of Measured LED Intensity Data Showing Occupancy Sensor Effect.........9 


\subsection{Introduction}

This report describes the process and results of a demonstration of solid-state lighting (SSL) technology combined with occupancy sensors in a set of upright grocery store freezer cases. The project was supported under the U.S. Department of Energy (DOE) Solid-State Lighting GATEWAY Technology Demonstration Program. Other participants in the demonstration project included, LED Power Inc., Aztec Energy Partners, Portland Energy Conservation, Inc (PECI), Eugene Water and Electric Board, and Albertsons ${ }^{\circledR}$ (a division of SuperValu ${ }^{\circledR}$ ). Pacific Northwest National Laboratory (PNNL) conducted the measurements and analysis of the results. PNNL manages a number of related demonstrations for DOE and represents their perspective in the conduct of the work.

DOE supports such demonstration projects to develop real-world experience and data with SSL products in general illumination applications. DOE's approach is to carefully match applications with suitable products and form such collaborative teams to carry out the needed project work. Other project reports and related information are available via DOE's SSL website at www.ssl.energy.gov/demos.

LED Power, Inc., manufactures a series of LED striplights applicable to freezer and refrigerator cases as direct replacements for typical linear fluorescent striplights. The manufacturer approached PNNL and Albertsons with a proposal to investigate LED freezer case lighting combined with occupancy sensors in a typical grocery aisle setting

A location for the demonstration was selected at Albertsons \#507 at 1685 West $18^{\text {th }}$ Avenue in Eugene, OR. The store employs a typical layout of parallel sets of freezer and refrigerator aisles that allows for direct side-by-side comparisons of the existing fluorescent and new LED technologies.

LEDs increase in efficacy at lower temperatures, in contrast with fluorescent technology whose output decreases with decreasing temperature. Because of the low temperature operating environment in food storage applications, LED lighting is better suited for it than fluorescent and energy savings may thereby be gained from its substitution. In addition to the potential for power and energy savings, other application advantages of the LED lighting include a much longer potential lifetime.

The LED luminaires were provided by LED Power and installed by Aztec Energy Partners in January of 2009. 


\subsection{Methodology}

\subsection{Site Description}

The test location is an aisle of freezer cases storing a variety of frozen food items at or just below 0 degrees F. The retrofit side of the aisle includes four 5-door cases and two 3-door cases facing into the aisle capped by similar cases on each end. The opposite side of the aisle contains a similar case setup. Each case is lighted with vertically mounted linear fluorescent lamps between doors. The store aisles were lighted with standard overhead strip fluorescent luminaires aligned parallel with the aisles which are typically on 24 hours a day due to cleaning and stocking activities. The store is open from 6 AM to midnight during the week and freezer case stocking is done primarily Monday, Wednesday, and Friday from Midnight to 4 AM. Cleaning is typically scheduled Monday through Friday after closing. The cases are illuminated continuously with no provision for turning case lights off after business hours.

\subsection{Pre-Retrofit Luminaires}

Albertsons initially used Sylvania Octron F040/835/XP/ECO 5' lamps in its freezer cases. This product is a T8 lamp rated at nominally 40 watts with 36,000 hour rated life and Correlated Color Temperature of $3500 \mathrm{~K}$, Color Rendering index of 82, and initial and mean lumen output of 3750 and 3560 .

\subsection{New Luminaires}

The replacement LED lighting strips were models SFBL18-84-57"-41K-24 (end of case $1 / 2$ at 445 initial lumens at 12.5 watts) and DFBL18-168-57"41K-24 (middle of case full at 850 initial lumens at 25 watts) provided by LED Power, inc. shown in Figure 1. For the 5 door cases the combination of two ends and four middle strips provide a nominal total of 4250 lumens at a nominal 125 watts for a calculated efficacy of 34 lumen/watt. For the 3 door cases the combination of two ends and two middle strips provide a nominal total of 2550 lumens at a nominal 75 watts. The units were driven by Advance model "LED120A0024V33F", 80 watt, 24 volt units shown in Figure 2. 


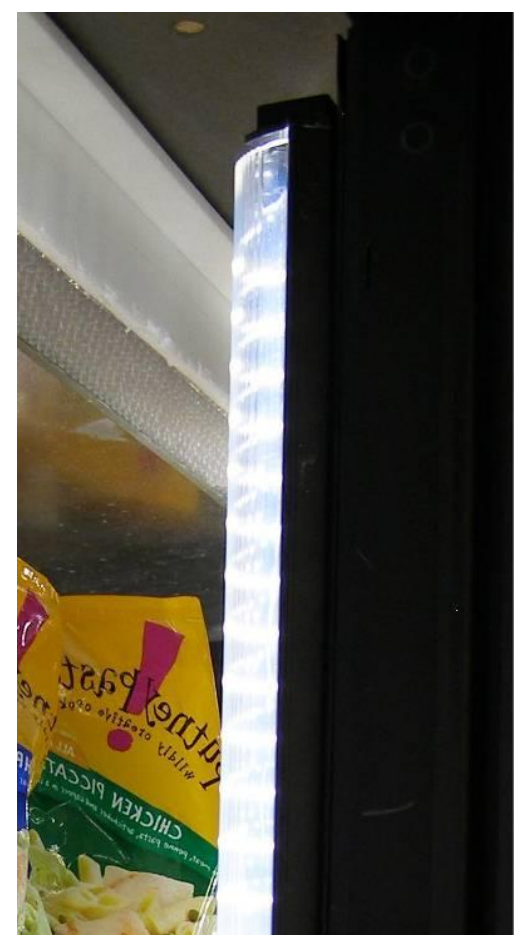

Figure 1. Top of LED Power LED strip as installed

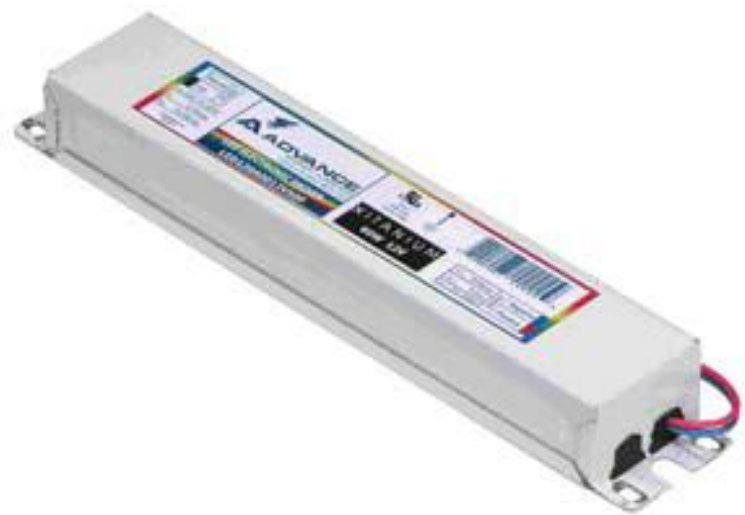

Figure 2. Advance LED driver LED120A0024V33F

\subsection{Installation}

The Lighting in the freezer cases was retrofitted with the new LED lighting on the morning of January 19. Due to the logistics of the test arrangement, the existing fluorescent lamps were not replaced and luminaires were not cleaned prior to the taking of lighting and power measurements.

The installation was staged starting at the end of the row with the 5-door cases as shown in Figure 3. Aztec Energy Partners staff proceeded to replace the fluorescent systems one case at a time. Prior to the first retrofit, measurements of luminance were taken through one door of this initial case to 
establish the baseline for that case. The combined measurement and installation process was continued until all base measurements were taken and all cases retrofit. PNNL staff undertook identical post-retrofit measurements on each case as its retrofit was completed.

After the LED installation was complete, the Aztec crew proceeded to install the occupancy sensors located on top of and centered for each of the 5-door and 3-door cases. The sensor units installed were an LED Power Developed Occupancy Sensor Control System that works in conjunction with a WattStopper model FS-705. Functional testing of the occupancy sensor operation and spot checks of the case luminaire luminance at the full and occupancy sensor reduced levels was also completed.

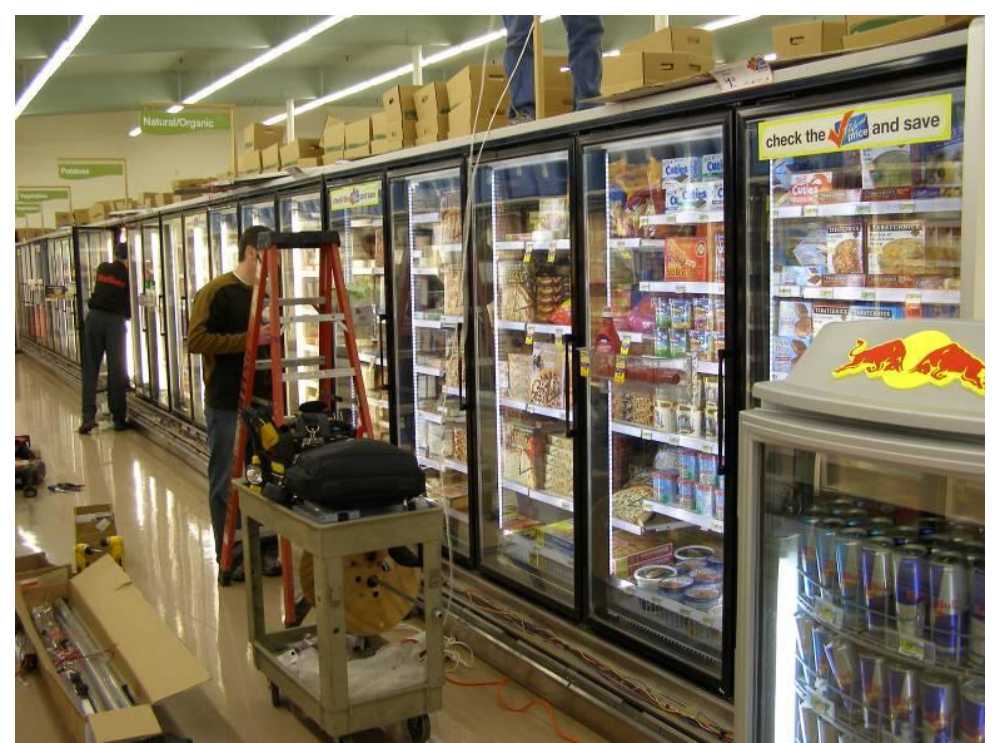

Figure 3. LED strip installation starting at one end of row

\subsection{Luminance Measurement}

Because the light of primary interest is that illuminating the face of shelves and product within the operating freezer case, a relative measurement system was necessary because the measurement of illuminance from within the case was not considered practical. Instead, a system that measures the luminance reflecting from a surface at the front of the shelving was employed. Product package differences in color and reflectivity are known to be a problem for uniform measurements, so a portable measurement surface placed inside the case was used to produce consistent and repeatable measurements.

The measurement protocol developed for these tests started with cleaning of the selected test doors inside and out to ensure uniformity of measurement. The method for capturing the luminance across the door viewing area involved the use of relatively white, diffuse-reflectance stiff card stock placed at the face of the shelves behind a freezer door shown in Figure 4. The card was marked with a grid of 1 inch circles spaced 6 inches apart in both directions. The card was positioned in each door relative to a repeatable location reference (shelf, edge of door) for pre- and post-retrofit conditions. After placement, the door was closed and allowed to defrost. 
Measurements were taken in two methods at a distance of approximately two feet away from the door surface. One set of measurements was taken perpendicular to each measurement circle through the door. A second set of measurements was taken from a typical customer viewing location. The first set of data eliminates potential door surface reflection which can be considered a more consistent method of measurement, while the second set are considered more realistic given they represent a more typical customer view of the product.

Measurements were taken with a Photo Research Luminance meter incorporating a Spot Mate attachment with a $1^{0}$ view angle. This instrument and the 1 inch circles on the card allowed for measurement at the proper location (at each circle) but measuring only white card surface (inside each circle) shown in Figure 5. See Appendix A for all pre and post individual case retrofit measurements. Results of an analysis of the case door measurements are as follows, showing average; maximum-to-minimum ratio; and Coefficient of Variation for both the fluorescent and LED conditions:

\section{Luminance $\left(\mathrm{cd} / \mathrm{m}^{2}\right)$ at front of shelves inside case:}

Typical Fluorescent Case

301.4 average

2.4 maximum-to-minimum ratio

0.20 Coefficient of Variation (CV)

Typical LED Case

192.3 average

2.7 maximum-to-minimum ratio

0.21 Coefficient of Variation (CV)

The resulting average reduction in luminance from the retrofit to LED lighting is calculated to be approximately $36.0 \%$. 


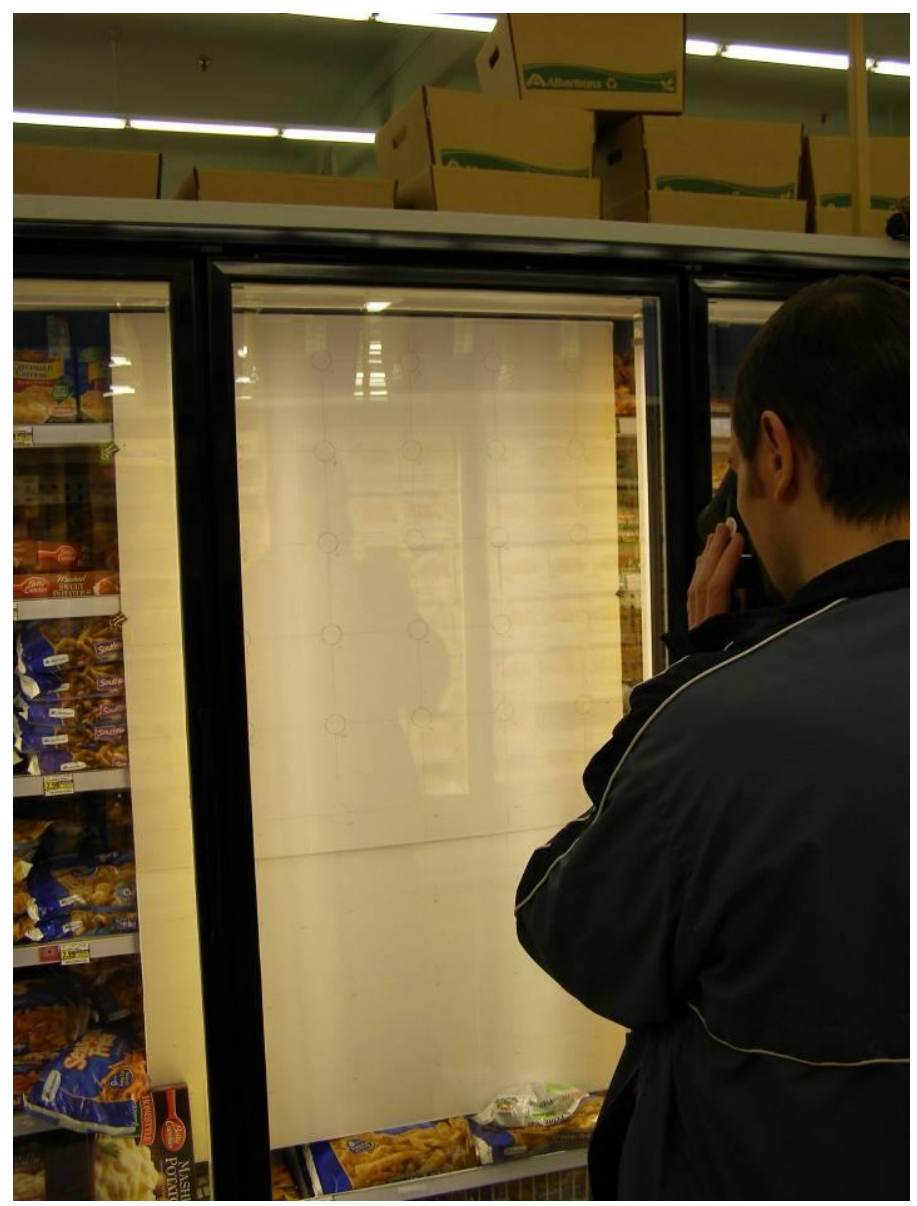

Figure 4. Luminance measurement of white test surface inside of case

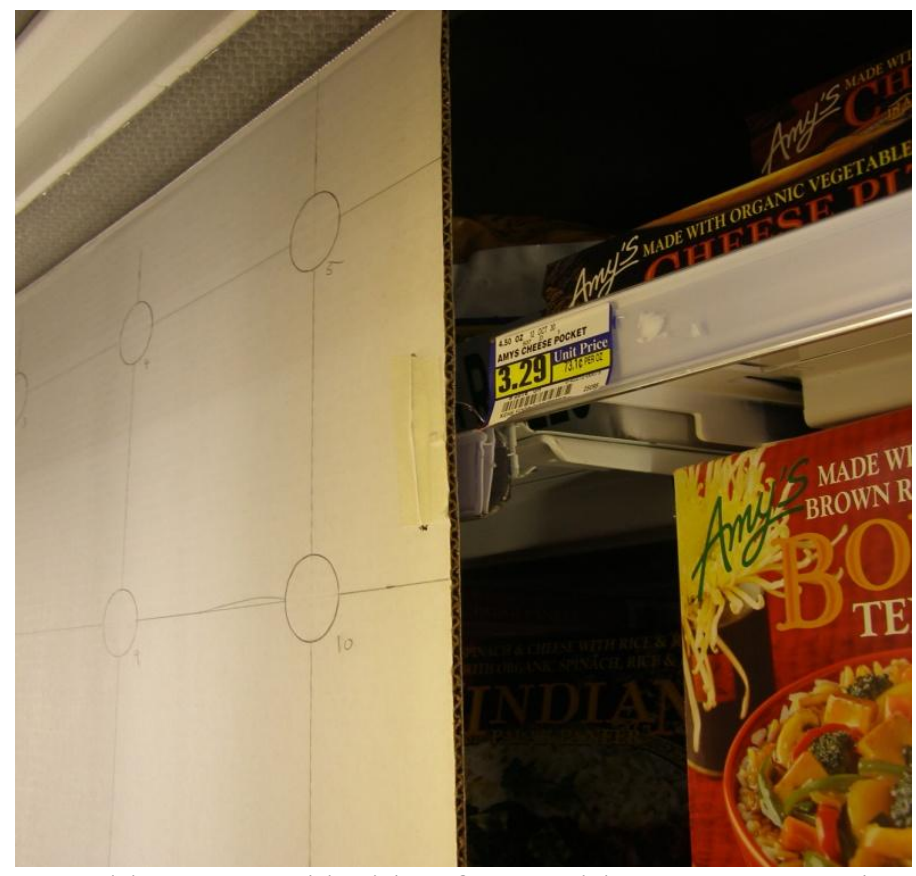

Figure 5. White test card inside of case with measurement locations 


\subsection{Occupancy Control Measurement}

The occupancy sensors installed as part of the system are designed to drop the power draw of the system down to $20 \%$ of full power after 30 seconds of no activity. The system operates such that the presence of occupants will only increase the illuminance of nearby cases to full output and not the entire aisle. When patrons pass near an end of the aisle, only the lighting in the case closest to the end of the aisle increases. Patrons must walk down the aisle to illuminate adjacent cases in that aisle.

Energy savings from this system were estimated based on data collected with the use of temporary lighting intensity loggers placed inside each case at the top of the installed LED strip in each case as shown in Figure 6. The sensors recorded relative lighting intensity and were thus able to capture the $100 \%$ and $20 \%$ power states of the LED lighting, as controlled by the occupancy sensors. Energy savings were later calculated using the time the lighting was on in each state multiplied by the corresponding power draw, summed up over the entire measurement period and compared against the baseline fluorescent value.

The loggers used were Hobo model UA-002-64. A total of six units were installed inside the cases and remained for a period of approximately two weeks after the retrofit. The resolution of the loggers was set to a reading level of every 20 seconds to capture energy savings as accurately as possible while allowing for the longest test period possible. In this case, the 20 second setting allowed approximately 2 weeks of recorded data from January 19 to February 3, 2009.

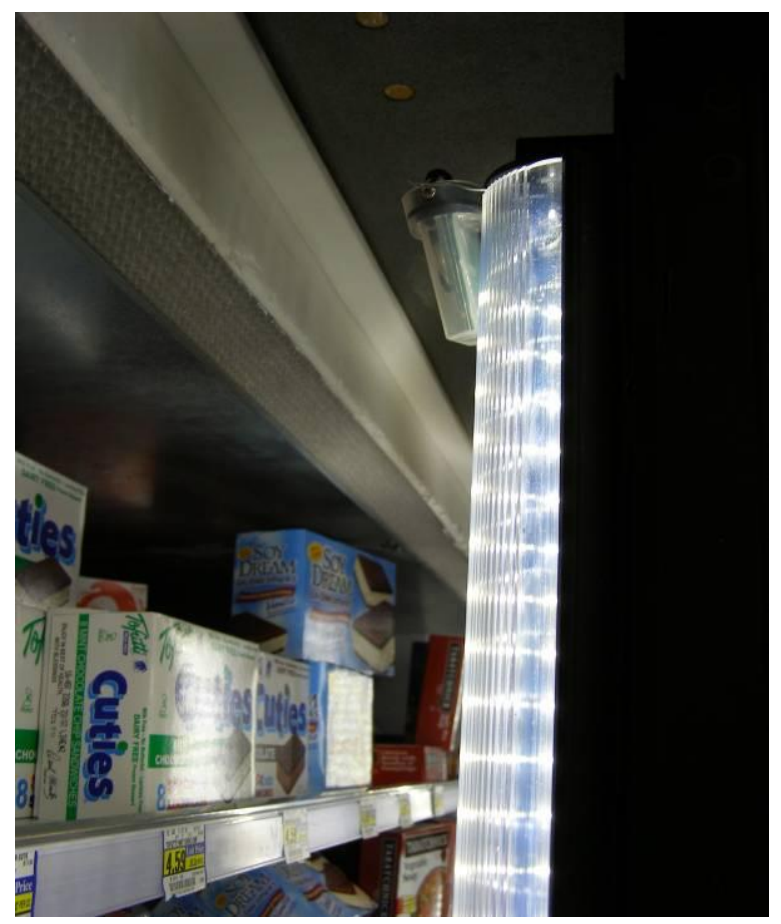

Figure 6. Hobo Light Level Logger installed at top of new LED light strip. 


\subsection{Energy Savings and Economics}

\subsection{Energy Savings Analysis}

Energy savings exists on several levels due to the retrofit to LEDs, the use of occupancy sensors, and an estimate of associated compressor savings. Each of these is estimated to be as shown in Table 1 and described below:

Table 1. Summary of Energy Savings for Single 5-door Refrigerated Case

\begin{tabular}{|l|c|c|}
\hline Savings Type & $\mathbf{k W H} /$ Year & Percentage of FL baseline \\
\hline Wattage Reduction & 1,682 & $61 \%$ \\
\hline $\begin{array}{l}\text { Occupancy Sensor } \\
\text { Reduction }\end{array}$ & 322 & $12 \%$ \\
\hline Total Lighting Savings & $\mathbf{2 , 0 0 4}$ & $\mathbf{7 3 \%}$ \\
\hline & & \\
\hline $\begin{array}{l}\text { Compressor Operation } \\
\text { Reduction }\end{array}$ & 655 & NA \\
\hline Total Retrofit Savings & $\mathbf{2 , 6 5 9}$ & NA \\
\hline
\end{tabular}

The total estimated savings of 2,659 kWh per year for a 5 -door case represents a $73 \%$ savings of the lighting itself plus the additional $655 \mathrm{kWH}$ of compressor energy.

Note that part of the energy savings associated with the change from fluorescent technology to LED technology is a result of the $36 \%$ relative reduction in light level in the case measured with the retrofit. It is not clear simply from the measured reduction that the $36 \%$ reduction has any known effect on patron viewing of products (i.e., whether they would even notice) and therefore purchasing habits. Observations during the tests indicate that changes in color of the light, uniformity, and light level are not immediately obvious even in a side by side comparison. This is attributed to the widely varying nature of the product packaging and the understanding within the lighting industry that illumination differences on the order of $30 \%$ are just at the threshold of recognition. Packaging or products of a more uniform nature would be more likely to show these effects.

\section{Wattage reduction from fluorescent to LED:}

The simplest energy reduction is the difference in wattage between the fluorescent and new LED lighting. The average fluorescent lighted 5-door case has measured amperage of 2.6, while the replacement LED lighting pulls only $1.0 \mathrm{amp}$. Actual voltage on building systems is not always as designed and not always consistent throughout a day or season. However, a basic estimate of savings can be calculated using a constant voltage assumption realizing that exact savings requires a measure of true power. In this case, the assumption of a uniform voltage of 120 for both existing and retrofit cases is used and the average wattage reduction per 5-door case is calculated at ( $(2.6-$ $1.0)^{*}(120)=192$ watts.

Based on 24 hour operation of the case lighting (store open 18 hours per day but the case lighting not turned off after hours), the estimated total yearly energy use of a typical 5-door case lighted with the fluorescent system used at the Albertsons store is: 2.6 amps*120 volt*24*365 $=2,733 \mathrm{kWh}$. The 
corresponding yearly energy use for the retrofitted LED system is: $1.0 \mathrm{amp} * 120$ volt*24*365 = 1,051 kWh. The estimated savings from one 5-door case lighted with LED Power model SFBL1884-57"-41K-24 and DFBL18-168-57"41K-24 LED strips (4 full plus 2 halves) in place of fluorescent lighting (6 lamps) is: 2733 - $1051=\mathbf{1 , 6 8 2} \mathbf{~ k W h}$ per year $(\mathbf{6 1 \%}$ savings - based in part on a relative $36 \%$ reduction in case illuminance)

\section{Occupancy sensor $80 \%$ of full power reduction:}

Occupancy sensors installed on individual cases reduce LED lighting power to $20 \%$ of full power for an $80 \%$ reduction in energy when no motion is detected for 30 seconds. Sensors are placed per case so that lights will come on and off only when patrons approach each case. The sample data in Table 2 provides a small 5 minute example of the effect of the occupancy sensor control as patrons move through an aisle. The zero values in the table are measurements of near zero intensity indicating that the LED case lights are off because of lack of occupancy near the case.

Approximately 12 days of data were recorded in this manner and the amount of time when case lighting was off was summed for the entire period. These data were further turned into percentages. The measured percentage of time that a case operated at only $20 \%$ of full power averaged over all 6 cases is calculated to be $38.3 \%$

Table 2. Sample of Measured LED Intensity Data Showing Occupancy Sensor Effect

\begin{tabular}{|c|c|c|c|c|c|c|c|}
\hline Sample & Time Stamp & Logger1 & Logger2 & Logger3 & Logger4 & Logger5 & Logger6 \\
\hline$\ldots .$. & $\ldots$. & $\ldots .$. & $\ldots .$. & $\ldots \ldots$ & $\ldots \ldots$ & $\ldots \ldots$ & $\ldots \ldots$ \\
\hline 157 & $1 / 19 / 0916: 52$ & 121 & 126 & 136 & 128 & 128 & 123 \\
\hline 158 & $1 / 19 / 0916: 52$ & 121 & 125 & 136 & 127 & 128 & 123 \\
\hline 159 & $1 / 19 / 0916: 52$ & 122 & 125 & 136 & 126 & 128 & 123 \\
\hline 160 & $1 / 19 / 0916: 53$ & 0 & 0 & 136 & 128 & 128 & 123 \\
\hline 161 & $1 / 19 / 0916: 53$ & 0 & 0 & 0 & 127 & 128 & 123 \\
\hline 162 & $1 / 19 / 0916: 53$ & 123 & 127 & 0 & 0 & 128 & 123 \\
\hline 163 & $1 / 19 / 0916: 54$ & 122 & 126 & 0 & 0 & 0 & 126 \\
\hline 164 & $1 / 19 / 0916: 54$ & 124 & 0 & 136 & 0 & 0 & 0 \\
\hline 165 & $1 / 19 / 0916: 54$ & 122 & 126 & 136 & 0 & 0 & 128 \\
\hline 166 & $1 / 19 / 0916: 55$ & 122 & 126 & 0 & 0 & 0 & 0 \\
\hline 167 & $1 / 19 / 0916: 55$ & 122 & 126 & 0 & 0 & 128 & 125 \\
\hline 168 & $1 / 19 / 0916: 55$ & 122 & 126 & 136 & 128 & 128 & 124 \\
\hline 169 & $1 / 19 / 0916: 56$ & 122 & 126 & 136 & 128 & 128 & 124 \\
\hline 170 & $1 / 19 / 0916: 56$ & 122 & 126 & 136 & 128 & 128 & 124 \\
\hline$\ldots .$. & $\ldots .$. & $\ldots .$. & $\ldots .$. & $\ldots .$. & $\ldots .$. & $\ldots .$. & $\ldots .$. \\
\hline
\end{tabular}

To further simplify this effect for estimating energy savings, the reduced operating time (38.3\%) and full operating time (remaining 61.7\%)values are averaged (weighted) to derive an overall percentage reduction in relative full power operating hours. This value is calculated as: $(0.383 \times 0.20)+(0.617$ $\mathrm{x} 1.00)=69.3 \%$ of relative full power hours use or $30.7 \%$ reduction in the relative full power hours compared to a constant-on LED system. 
Based on a 24 hour operating store, that includes stocking and cleaning most days, the estimated total energy savings from occupancy sensor control of an LED lighted 5-door case (4 full plus 2 halves $=120 \mathrm{~W})$ is $(1,051 * 0.307)=\mathbf{3 2 2} \mathbf{k W h}$ per year (additional $\mathbf{1 2} \%$ savings from fluorescent baseline)

For comparison, a similar control could be implemented on the fluorescent system with a change in ballast to one with step dimming capability. Based on 24 hour operations the estimated total energy savings from occupancy sensor control ONLY on a standard fluorescent lighted 5-door case (6 lamps $=312 \mathrm{~W})$ would be: $\mathbf{8 3 6} \mathbf{k W h}$ per year. However, the fluorescent system would still consume more power than the LED system because of its higher illuminance within the case during both 100\% and 20\% operation. The operation of fluorescent technology is also typically less efficient at lower output, hence $20 \%$ operation of a fluorescent system would decrease its efficiency in general.

\section{Compressor savings estimate:}

The freezer case compressor will see a reduction in energy use based on the reduced lighting energy (heat introduced into the case) that must be removed. In actuality the absolute effect of reduced lighting energy on case cooling load will vary depending on a number of conditions including type of product displayed in the cases, its loaded temperatures, loading schedule, case operating conditions, seasonal differences, and ambient temperatures among others. These variables are difficult to accurately measure for individual cases and metering and analysis has already been completed for other similar case studies resulting in an applicable estimate of savings based on changes in lighting load and refrigeration equipment Coefficient of Performance (COP $)^{2}$. The refrigeration equipment $\mathrm{COP}$ which relates the equipment's efficiency at removing heat and the actual difference in heat introduced into the case from the new lighting retrofit (3.41 Btu per Watt of lighting energy) can be used to estimate the reduction in refrigeration compressor energy.

Therefore, to avoid the need for extensive additional monitoring of the specific case refrigeration equipment and surrounding conditions, an estimated value of the savings was used based on the previous work. For freezer cases, the previous work indicated typical COP value of 1.4 and the estimate of compressor savings for a 5 -door case is:

[(Reduced wattage in $\mathrm{kWh} / \mathrm{COP}) \times$ relative full hours per year]

For this set of tested cases the ballasts and therefore LED drivers were installed outside of the refrigerated portion of the case and therefore any ballast or driver losses (heat) is not introduced into the case and therefore not counted. Some small part of the light produced by the lamps exits the case and should also not be counted. A conservative estimate of the actual thermal energy introduced into the case from the fluorescent lamp or LED that must be subsequently removed by the refrigeration compressor is $79 \%$ of the wattage difference, based on the lighting energy road mapping provided by the IES handbook ${ }^{3}$.

Therefore the additional compressor savings estimate for a 5-door case is calculated to be: $((192 / 1000) \times 0.79 / 1.4) \times(52 \times 7 \times 24 \times 0.693)=655 \mathbf{k W h}$ per year (additional $24 \%$ savings from fluorescent baseline)

\footnotetext{
2 “LED Refrigerated Case Lighting Costco, Northern California” (Appendix C-2), Application Assessment Report \#0722, Pacific Gas and Electric Company, EMCOR Energy Services, May 2008

${ }^{3}$ IES Handbook, $9^{\text {th }}$ edition, Figure 6-34, page 6-29
} 


\subsection{Payback Economics}

An analysis of simple payback based on energy savings only for this application incorporates the estimated typical cost of the complete installed system (LED + occupancy sensors + typical labor to install) and the standard April 2009 DOE reported $\mathrm{kWh}$ energy rate for Oregon of $\$ 0.0827^{4}$. The total estimated cost provided by LED Power for the lighting equipment plus an occupancy sensor and installation labor for a 5 door case is $\$ 1,387$ as follows:

(4) mullion light bars (\$185 each) \$740

(2) single (end) light bars (\$111 each) \$222

Installation (\$60 per door) \$300

Occupancy sensor and installation $\$ 125$

Total $\$ 1,387$

Savings of 2,659 kWh per year at the energy rate of $\$ 0.0827$ provides an estimated cost savings of $\$ 220$ per year. Based on these values, the simple energy only payback is calculated at 6.3 years.

Maintenance savings which are much more difficult to estimate would reduce the complete simple payback even further depending on many variables including the actual life of the fluorescent products and the LED products as well as replacement and labor costs. One estimate based on fluorescent lamp replacement costs (material + labor) of $\$ 12$ per lamp and assuming a 2 year replacement cycle for fluorescent lamps leads to an estimated yearly maintenance savings of $\$ 36$ per year. Incorporating this additional savings would further reduce the payback to about 5.4 years.

A complete payback analysis could also include other cost reduction items such as utility rebates and maintenance savings. For this specific demonstration application located in Oregon, there is a current Energy Smart rebate of $\$ 40$ per lineal foot of refrigerator case which for the 5 door case is approximately $\$ 500$ and could be a nearly direct up-front reduction in installed cost. Oregon also currently has a $35 \%$ of installed cost Tax Credit that would be $\$ 485$ which would not be immediate but could be considered a part of the overall payback analysis. Applying these two additional cost reductions would create a revised payback of only 1.6 years.

\footnotetext{
${ }^{4}$ http://www.eia.doe.gov/cneaf/electricity/epm/table5_6_a.html
} 


\subsection{Discussion}

The results of the retrofitted case lighting were considered to be a positive change compared to the standard lighting on the opposite side of the aisle by the store staff. Although the light levels were lower with the LED lighting, and the effect could be seen with a side by side comparison of a retrofitted and original case (see Figure 4.7), the effect was not as obvious when the complete row was retrofitted. One basic observation is that the variety of the packaging within the cases masked the difference in light level and any changes in uniformity. No formal customer responses were captured but the few patrons offering input had only positive comments.

A primary result of this retrofit was a 36\% light level reduction with the retrofit LEDs, which accounts for more than half of the energy savings. This reduction in light levels may also have been accomplished by retrofitting different fluorescent technology in the form of a lower output lamp and/or lower driving ballast. However, the complete retrofit incorporating step dimming based on occupancy might be more difficult with fluorescent technology given the limited market offerings of specific dimming ballast technology. Another related issue with case lighting is that light levels found in refrigerated cases are typically well above the IES illuminance recommendations. This is likely in part a fluorescent product offering issue where limited lamp output options make it difficult to outfit cases with lower lighting levels.

Other potential attributes of LEDs make them a potentially better retrofit than adjusted fluorescent lighting in freezer case applications. These include the potentially longer life and reduced freezer case heat load that contributes to additional savings with LED technology.

The potential for more uniform distribution of lighting is a potential capability with LED luminaire design and application. This was evaluated in this application and the LED system was found to be just slightly less uniform then the fluorescent. However, in the case of product cases where widely varying package graphics and colors are the norm, the limited personal observation from this study shows little noticeable difference in case product viewing due to this uniformity issue alone.
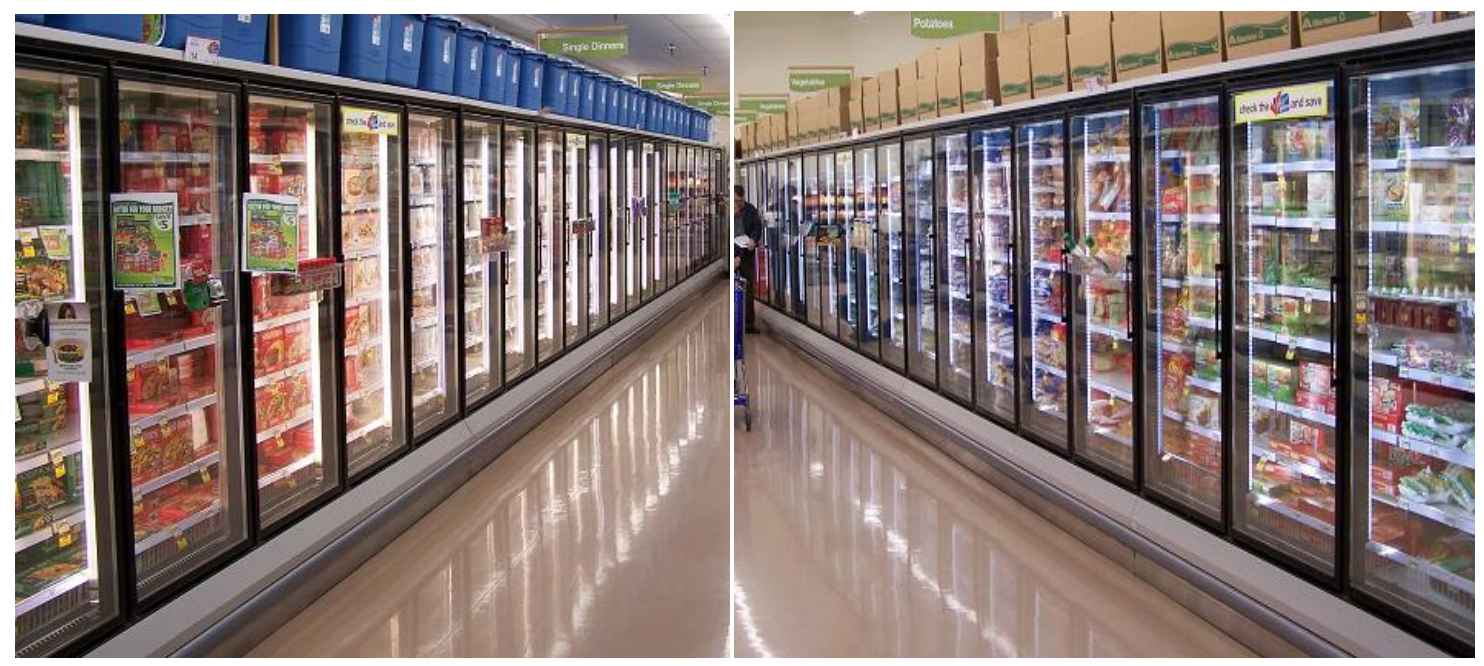

Figure 7. Side-by-Side Fluorescent (left) to LED (Right) Comparison 
Appendix 


\section{Case 13}

Fluorescent luminaires

Luminance measured perpendicular to door

\begin{tabular}{|lllll|}
\hline 180.7 & 186.2 & 172.1 & 206.0 & 165.3 \\
305.6 & 278.0 & 268.9 & 326.2 & 295.9 \\
338.1 & 321.5 & 308.8 & 365.7 & 337.6 \\
353.7 & 344.1 & 317.8 & 375.3 & 344.7 \\
360.1 & 347.9 & 306.1 & 376.9 & 352.6 \\
339.3 & 338.1 & 302.6 & 375.2 & 351.1 \\
332.9 & 335.1 & 305.3 & 370.1 & 343.9 \\
308.6 & 315.3 & 287.4 & 340.1 & 337.7 \\
277.5 & 278.8 & 248.4 & 304.0 & 307.5 \\
\hline 309.7 & avg & & & \\
2.3 & max:min & & & \\
0.18 & CV & & & \\
\end{tabular}

LED luminaires

Luminance measured perpendicular to door

\begin{tabular}{|lllll|}
\hline 143.2 & 92.7 & 164.2 & 100.6 & 146.6 \\
204.1 & 146.8 & 240.4 & 154.1 & 207.8 \\
212.3 & 151.0 & 269.2 & 168.5 & 210.7 \\
222.3 & 164.4 & 280.6 & 170.2 & 213.3 \\
219.4 & 161.7 & 264.2 & 166.3 & 212.9 \\
208.6 & 156.9 & 271.9 & 164.3 & 227.3 \\
209.2 & 163.0 & 266.8 & 160.7 & 215.8 \\
202.5 & 161.5 & 236.9 & 153.8 & 214.2 \\
191.5 & 140.7 & 193.4 & 132.1 & 198.1 \\
\hline 190.1 & avg & & & \\
3.0 & max:min & & & \\
0.23 & CV & & & \\
\hline
\end{tabular}

Fluorescent luminaires

Luminance measured from eye level at center of door

\begin{tabular}{|lllll|}
\hline 202.4 & 214.0 & 199.7 & 226.1 & 196.8 \\
321.1 & 300.7 & 281.2 & 337.8 & 310.3 \\
368.3 & 351.6 & 302.8 & 378.9 & 347.7 \\
392.7 & 356.1 & 315.5 & 393.8 & 364.0 \\
395.8 & 358.9 & 310.8 & 403.8 & 366.4 \\
378.1 & 359.7 & 305.8 & 388.4 & 366.0 \\
364.9 & 348.6 & 304.0 & 368.5 & 357.7 \\
341.9 & 340.2 & 296.4 & 350.1 & 347.4 \\
309.9 & 298.0 & 252.0 & 314.1 & 321.6 \\
\hline 326.9 & avg & & & \\
2.1 & max:min & & & \\
0.17 & CV & & &
\end{tabular}

LED luminaires

Luminance measured from eye level at center of door

\begin{tabular}{|lllll|}
\hline 170.6 & 126.1 & 188.1 & 127.6 & 173.4 \\
205.2 & 147.8 & 240.4 & 166.4 & 216.1 \\
236.7 & 166.8 & 276.0 & 179.5 & 246.5 \\
234.6 & 161.4 & 272.2 & 165.6 & 228.7 \\
221.8 & 158.0 & 268.2 & 163.2 & 227.9 \\
210.4 & 166.7 & 262.6 & 164.8 & 231.4 \\
203.4 & 171.7 & 261.4 & 163.7 & 234.0 \\
213.8 & 165.2 & 227.7 & 156.3 & 221.1 \\
195.3 & 148.3 & 179.3 & 131.7 & 207.6 \\
\hline 197.4 & avg & & & \\
2.2 & max:min & & & \\
0.21 & CV & & & \\
\hline
\end{tabular}




\section{Case 14}

Fluorescent luminaires

Luminance measured perpendicular to door

\begin{tabular}{|lllll|}
\hline 155.9 & 167.7 & 147.8 & 169.6 & 148.1 \\
252.0 & 269.9 & 252.2 & 265.3 & 245.3 \\
312.0 & 292.5 & 267.3 & 298.1 & 276.8 \\
328.4 & 325.7 & 278.6 & 306.6 & 279.3 \\
315.7 & 322.3 & 272.8 & 315.0 & 282.4 \\
319.3 & 325.9 & 274.8 & 306.4 & 279.3 \\
304.2 & 309.7 & 266.4 & 301.3 & 274.6 \\
303.4 & 299.9 & 264.7 & 302.5 & 265.5 \\
278.2 & 263.1 & 230.9 & 260.9 & 244.1 \\
\hline 271.6 & avg & & & \\
2.2 & max:min & & & \\
0.17 & CV & & & \\
\end{tabular}

LED luminaires

Luminance measured perpendicular to door

\begin{tabular}{|lllll|}
\hline 151.6 & 97.4 & 138.6 & 98.2 & 137.9 \\
217.5 & 160.0 & 198.4 & 153.0 & 205.4 \\
219.9 & 172.2 & 212.3 & 172.9 & 223.7 \\
233.7 & 182.8 & 205.9 & 170.5 & 221.5 \\
230.2 & 180.4 & 190.9 & 169.1 & 232.1 \\
221.4 & 173.6 & 200.0 & 159.3 & 232.6 \\
214.4 & 166.8 & 238.6 & 158.3 & 222.0 \\
213.1 & 157.0 & 217.3 & 150.7 & 227.3 \\
210.1 & 136.8 & 179.4 & 132.8 & 218.3 \\
\hline 186.8 & avg & & & \\
2.4 & max:min & & & \\
0.20 & CV & & & \\
\end{tabular}

Fluorescent luminaires

Luminance measured from eye level at center of door

\begin{tabular}{|lllll|}
\hline 173.2 & 182.0 & 165.6 & 175.3 & 169.7 \\
257.7 & 262.8 & 230.5 & 255.7 & 243.0 \\
327.0 & 336.6 & 271.2 & 330.3 & 313.9 \\
310.8 & 317.3 & 267.5 & 312.7 & 326.4 \\
316.5 & 325.0 & 265.0 & 314.7 & 287.6 \\
322.9 & 331.1 & 262.8 & 324.1 & 296.6 \\
309.1 & 308.0 & 259.9 & 306.8 & 269.6 \\
312.8 & 295.0 & 249.5 & 298.6 & 267.6 \\
285.6 & 263.5 & 209.0 & 267.8 & 245.8 \\
\hline 276.1 & avg & & & \\
2.0 & max:min & & & \\
0.17 & CV & & &
\end{tabular}

LED luminaires

Luminance measured from eye level at center of door

\begin{tabular}{|lllll|}
\hline 181.1 & 117.4 & 140.5 & 106.9 & 161.7 \\
217.2 & 168.7 & 204.3 & 159.4 & 204.0 \\
255.1 & 213.3 & 217.8 & 192.1 & 258.0 \\
240.1 & 186.9 & 205.0 & 168.5 & 282.0 \\
250.0 & 187.7 & 197.8 & 174.7 & 237.3 \\
232.5 & 182.0 & 196.9 & 177.9 & 245.2 \\
241.6 & 180.0 & 248.2 & 169.5 & 239.7 \\
227.1 & 160.9 & 216.1 & 159.0 & 240.5 \\
209.0 & 146.9 & 171.8 & 142.0 & 228.7 \\
\hline 198.7 & avg & & & \\
2.6 & max:min & & & \\
0.20 & CV & & &
\end{tabular}




\section{Case 16C}

Fluorescent luminaires

Luminance measured perpendicular to door

\begin{tabular}{|lllll|}
\hline 170.8 & 215.4 & 179.6 & 184.2 & 158.4 \\
298.2 & 341.0 & 271.7 & 298.3 & 260.1 \\
360.3 & 386.8 & 309.9 & 335.4 & 300.8 \\
388.8 & 398.8 & 338.9 & 370.9 & 318.8 \\
397.9 & 382.2 & 331.9 & 362.7 & 317.4 \\
405.3 & 386.9 & 329.1 & 360.5 & 300.7 \\
392.7 & 405.2 & 324.4 & 355.2 & 290.4 \\
367.6 & 391.3 & 312.5 & 342.1 & 280.9 \\
325.0 & 357.0 & 277.9 & 298.7 & 269.8 \\
\hline 321.2 & avg & & & \\
2.6 & max:min & & & \\
0.20 & CV & & &
\end{tabular}

LED luminaires

Luminance measured perpendicular to door

\begin{tabular}{|lllll|}
\hline 155.1 & 101.6 & 172.0 & 103.3 & 152.5 \\
211.5 & 156.8 & 250.5 & 158.6 & 208.2 \\
231.5 & 168.6 & 286.7 & 174.0 & 216.6 \\
238.7 & 179.6 & 301.4 & 181.0 & 225.7 \\
227.5 & 168.6 & 283.0 & 234.9 & 173.8 \\
225.1 & 171.0 & 284.4 & 175.1 & 224.5 \\
242.5 & 175.0 & 285.8 & 168.7 & 227.4 \\
213.4 & 165.1 & 263.2 & 165.8 & 237.3 \\
208.3 & 146.7 & 215.6 & 135.5 & 205.4 \\
\hline 201.7 & avg & & & \\
3.0 & max:min & & & \\
0.24 & CV & & & \\
\hline
\end{tabular}

Fluorescent luminaires

Luminance measured from eye level at center of door

\begin{tabular}{|lllll|}
\hline 193.1 & 223.5 & 189.1 & 198.4 & 169.8 \\
303.9 & 330.1 & 265.9 & 297.1 & 261.5 \\
380.2 & 396.6 & 307.7 & 347.4 & 327.6 \\
402.8 & 387.1 & 324.2 & 357.1 & 327.4 \\
399.9 & 390.1 & 325.4 & 365.8 & 322.3 \\
409.0 & 404.2 & 318.5 & 370.2 & 318.4 \\
401.6 & 412.8 & 333.4 & 358.2 & 304.0 \\
384.3 & 393.9 & 314.0 & 337.6 & 291.8 \\
337.2 & 351.4 & 262.4 & 301.2 & 275.1 \\
\hline 326.1 & avg & & & \\
2.4 & max:min & & & \\
0.19 & CV & & & \\
\hline
\end{tabular}

LED luminaires

Luminance measured from eye level at center of door

\begin{tabular}{|lllll|}
\hline 170.5 & 112.6 & 177.2 & 112.7 & 159.5 \\
220.2 & 164.8 & 258.6 & 162.0 & 215.6 \\
238.3 & 181.9 & 294.3 & 174.5 & 232.2 \\
237.3 & 190.3 & 294.0 & 174.7 & 250.3 \\
282.2 & 170.8 & 225.6 & & \\
241.5 & 184.5 & 283.4 & 170.5 & 237.6 \\
239.4 & 182.0 & 280.6 & 172.3 & 232.8 \\
234.4 & 173.6 & 251.7 & 159.4 & 246.5 \\
213.0 & 149.1 & 201.9 & 137.2 & 217.8 \\
\hline 207.1 & avg & & & \\
2.6 & max:min & & & \\
0.23 & CV & & & \\
\hline
\end{tabular}




\section{Case 16R}

Fluorescent luminaires

Luminance measured perpendicular to door

\begin{tabular}{|lllll|}
\hline 161.0 & 189.3 & 176.1 & 184.6 & 171.3 \\
294.4 & 302.0 & 255.5 & 300.2 & 275.0 \\
336.5 & 358.4 & 294.1 & 338.8 & 321.7 \\
353.7 & 377.7 & 321.5 & 358.6 & 312.0 \\
348.8 & 371.1 & 315.7 & 352.0 & 315.9 \\
341.8 & 373.9 & 311.3 & 346.7 & 316.0 \\
316.8 & 370.4 & 306.9 & 333.4 & 283.5 \\
306.5 & 364.8 & 292.4 & 313.4 & 271.4 \\
298.1 & 327.4 & 258.5 & 271.7 & 244.5 \\
\hline 303.0 & avg & & & \\
2.3 & max:min & & & \\
0.18 & CV & & & \\
\end{tabular}

LED luminaires

Luminance measured perpendicular to door

\begin{tabular}{|lllll|}
\hline 154.5 & 103.9 & 135.5 & 119.3 & 138.2 \\
217.6 & 147.7 & 197.8 & 179.6 & 188.1 \\
243.5 & 170.2 & 218.1 & 190.2 & 207.0 \\
243.5 & 178.5 & 227.0 & 190.8 & 215.9 \\
232.1 & 167.2 & 207.9 & 194.7 & 211.6 \\
228.7 & 174.8 & 208.4 & 181.3 & 198.3 \\
233.9 & 179.2 & 239.7 & 169.9 & 200.1 \\
222.2 & 176.6 & 232.4 & 166.1 & 210.9 \\
214.3 & 148.2 & 188.0 & 143.7 & 182.5 \\
\hline 190.7 & avg & & & \\
2.3 & max:min & & & \\
0.18 & CV & & & \\
& & & &
\end{tabular}

Fluorescent luminaires

Luminance measured from eye level at center of door

\begin{tabular}{|lllll|}
\hline 184.7 & 234.7 & 184.2 & 210.6 & 205.5 \\
322.0 & 327.1 & 268.7 & 323.6 & 339.0 \\
361.9 & 375.8 & 316.1 & 370.7 & 360.4 \\
372.9 & 384.3 & 325.7 & 385.2 & 361.7 \\
362.6 & 391.2 & 325.5 & 378.6 & 329.9 \\
363.1 & 407.0 & 322.4 & 380.4 & 324.7 \\
348.8 & 406.8 & 318.5 & 365.3 & 316.1 \\
332.8 & 375.8 & 298.2 & 349.5 & 303.0 \\
322.3 & 344.0 & 265.5 & 293.7 & 280.4 \\
\hline 327.1 & avg & & & \\
2.2 & max:min & & & \\
0.17 & CV & & & \\
\hline
\end{tabular}

LED luminaires

Luminance measured from eye level at center of door

\begin{tabular}{|lllll|}
\hline 166.2 & 133.8 & 144.1 & 126.5 & 146.9 \\
226.2 & 158.3 & 200.2 & 180.5 & 192.9 \\
241.3 & 174.7 & 218.5 & 201.4 & 206.9 \\
249.6 & 168.4 & 212.0 & 184.6 & 220.9 \\
231.3 & 168.0 & 210.0 & 184.3 & 208.6 \\
235.3 & 181.4 & 209.0 & 181.3 & 207.7 \\
235.7 & 190.0 & 232.0 & 171.7 & 213.9 \\
223.7 & 164.9 & 217.0 & 163.9 & 207.3 \\
215.1 & 150.5 & 169.4 & 142.1 & 188.0 \\
\hline 192.4 & avg & & & \\
2.0 & max:min & & & \\
0.16 & CV & & & \\
\hline
\end{tabular}

